\title{
The model of psycholinguistic image analysis
}

\author{
Ekaterina Balandina - Tatiana Peredrienko
}

DOI: 10.18355/XL.2019.12.02.01

\begin{abstract}
The article aims to present the model of psycholinguistic image analysis by studying the image "money" in the linguistic consciousness of Arabic, Chinese and Russian students. The work performed from the position of psycholinguistic school gives the full and detailed analysis of the similarities and differences in perception of the universal material value "money". This perception is influenced not only by mass media, literature, social and political changes happening in society but also by subjective tendencies, interests, and ideals of an individual. The research is based on a postulate that any phenomena of reality perceived by a person in the process of his activity and communication are revealed in his linguistic consciousness. The image associated with the phenomenon or object can be studied using the associative experiment. The associative fields constructed in the course of the experiments allow analyzing the image "money" from the purely linguistic and psycholinguistic point of views according to the formal-grammatical features of the received responses, contiguity and similarity classification and semantic field grouping. The model of psycholinguistic image analysis presented in the article can be used for the analysis of other values and concepts existing in the linguistic consciousness of any culture representatives. Each nation has particular knowledge and stereotypes, specific value orientations and certain associations that are imprinted in the nation's worldview. The psycholinguistic image analysis helps to understand the difference between national cultures and find out their complementarity at the level of world culture.
\end{abstract}

Key words: psycholinguistic analysis, linguistic consciousness, associative experiment, associative field, verbal associations

\section{Introduction}

The problem of values is considered to be crucial in assessing the development level of modern society, as they determine motivation, norms, and behavior of community members. Value is an object of reality that is defined positively or negatively not by its properties, but by its involvement in the sphere of human life, interests and social relations. Criteria and evaluation procedures of any value are expressed in moral principles, norms, ideals, attitudes, and goals (Alefirenko, 2015; Vasilyeva, 2016; Burcu Bayram, 2016). Thus, a value is a product of the human mind, which engages in reasoning, abstract thought, and allows for intellectual insights (Robinson, 2016).

Young people, being the future and the most important component of a society, are of particular interest. The study of the younger generation makes it possible to establish and describe in details the interrelationship of problems in society with the changes taking place in the structure of the personality of members of this society, in the value and motivational sphere. It is important to remember that the problems of youth formation, its development, and successful identification are a reflection of how this society develops, in what direction it is going, which also confirms the relevance of the chosen topic. That is why more and more scientists choose a young generation as an object of their studies (Goggin, 2013; Soler-i-Martí and Ferrer-Fons, 2015; Burchell and Coutts, 2018; Childs, 2018 and other). Thus life value monitoring among young people is considered to be a relevant area of scientific research, as it allows to highlight real goals of a new generation and to reveal the real hierarchy of value orientations.

XLinguae, Volume 12 Issue 2, April 2019, ISSN 1337-8384, eISSN 2453-711X 
Money smoothly becomes an important factor that has a considerable impact on people's career orientation, choice of communication circles and lifestyle. Jennifer E. Stellar1 and Robb Willer note that people value money to such an extent that they will often act in immoral, exploitative ways to acquire it, evidence that appears consistent with a narrow view of human preferences as materialistic and selfish (Stellar and Willer, 2013). Matt Hampton remarks that money is re-examined as a moment of social power to command living labor, enforcing the moment of alienation that gives rise to the necessary commodity within capitalism - labor-power (Hampton, 2013). Nowadays the social and economic situation in the world is becoming very dynamic. The intensive development of the economy, changes in the social environment determine the restructuring of the individual value priorities following the new socioeconomic conditions. Qualitative changes that take place in modern society modify the economic essence of money as it becomes a psychologized phenomenon of culture, which significantly influences people's consciousness and behavior (Deineka, 2004). So in modern society money functions as an economic, social and cultural value and the role of it is continuously increasing. People have in their national consciousness a clear awareness of the importance and necessity of money as a mean for other achievements.

According to A. Wierzbicka's opinion, the national consciousness has different levels, and it contains the facts that are on the surface as well as the ones which are hidden very deeply (Wierzbicka, 1992). National consciousness verbalized in languages is called linguistic consciousness. John Field in his "Psycholinguistics: The Key Concepts" marks that psycholinguistics goes to the heart of what people do with language (Field, 2004). That is why psycholinguists offer to analyze cultural values through linguistic consciousness which is defined as a reflection of the objective world in a bilateral sign in which ideas of objects and phenomena of the world are connected with sound representations (Tarasov, 1996; Wierzbicka, 2005). So we can state that linguistic consciousness is a language-verbalized worldview of culture (Ufimtseva, 2003).

A person is a representative of a specific national culture that means that his linguistic consciousness has certain qualities that were formed under the influence of a particular national culture. Moving through culture shapes a series of experiences across the life-course, and these experiences "layer up" within individuals, forming complex sedimentation of culture within individuals (Zittoun, Gillespie, 2012). Linguistic consciousness consists of images and representations that are associated with words (more precisely with the bodies of linguistic signs) and are used by communicants to construct thoughts when coding and decoding speech messages (Tarasov, 1996). Thus, the differences of linguistic consciousness are the main cause of misunderstanding in intercultural communication, because any dialogue takes place only in the consciousness of a particular person and reflects the particular images existing in it (Ufimtseva, 2006). That is why the cross-cultural studies that have used nations as the units of analysis have been challenged on various grounds. One objection is that there may be significant cultural diversity within some countries and similarities across national borders, compromising the concept of national culture (Minkov, Hofstede, 2011). The specificity of linguistic consciousness study lies in the fact that the impossibility of its direct analysis forces scientists to find cognitive procedures that make linguistic consciousness accessible for research (Sergieva, 2009) and thus contribute significantly to avoiding cross-cultural miscommunication (Ming-chung, 2005).

As modern society becomes increasingly interconnected due to the growth of cultural exchanges and direct contacts between different countries with their histories (Gronbeck-Tedesco, 2017), it is crucial to organize the comparative analysis of images existing in linguistic consciousness of various culture representatives. It helps scientists to describe naïve understanding which is defined as a system of connected 
ideas about cultural models which are shared with other members of one's cultural group (Nguyen, 2016). Such research will reveal not only the system of linguistic consciousness that is influenced by different ethnic stereotypes but also will allow to trace similar and distinctive features of images and thus to identify the current development trends in the modern society.

\section{Methodology \\ Theoretical research base}

Human beings are not just sign-users and sign-interpreters, but also material agents that engage the material world and transform it for use, adding a "second nature" to the "first nature" out of which they have emerged. This second nature is, along with sign systems, an exosomatic body, infused with meaning. It is the technological or "made" world that along with fundamental nature is perceived as well as dealt with and which likewise informs the circuit of perception and action out of which we construct our worlds (Innis, 2016). The theoretical base for the analysis was the reasonable psycholinguistic idea that the phenomena of the reality perceived by a person in the process of activity and communication are revealed in his linguistic consciousness. This imaging records not only the causal and spatial relationships of phenomena and emotions in the process of perception but also can be characterized by a certain ethnocultural peculiarity, dynamism, and variability (Garnham, 1985; Kelly, 1996; Tarasov, 1996; Ufimtseva, 2004).

\section{Method}

In psycholinguistics, it was understood that neither dictionary definition nor the researcher's introspective analysis are enough to explain the processing of linguistic units and related issues. The way to overcome these restrictions is the usage of normative data for those units which emerge as a result of rating studies and detailed linguistic descriptions combined with various research methods (Miklashevsky, 2018). Psycholinguistics combines methods and theories from psychology and linguistics. It attempts to evaluate the reality and the underpinning of linguistic rules and processes. It also seeks to link a word processing to the deeper expressive processes of message construction and interpretation. Linguistic consciousness and images existing in it always remain hidden for the researcher and become available by means of the associative experiment which is defined as a method revealing the associations that an individual has in his previous experience (Deese, 1962; Jung, 1966; Leontiev, 1993; Ushakova, 2000; Zalevskaya, 2005; Sorokin, 2007; Zhalsanova, 2017). Association is understood as a connection formed between two or more mental entities. The effect of this connection is the actualization of the association (the appearance of one member of the association leads to the appearance of the other). The method aims to understand the associative series of the participants, to construct and analyze the associative relationships between various images. The technique of carrying out a free-associative experiment is that an examinee is given a questionnaire usually consisting of 100 words that have no logical connections and a person is to read every word and give a response that comes to his/ her mind as soon as possible, without restriction of formal and semantic features of the reaction word (Frumkina, 2001). Then the received results are analyzed, compared, worked out statistically and described. Through the described procedure that combines elements of linguistics and psychology, researchers are able to analyze what people think in real-world situations when they are uninfluenced by the trappings of scientific methodology (Taylor and Usborne, 2007). 


\section{Material}

The associative field, formed by the reactions received through the experiment helps to describe images existing in linguistic consciousness. It reflects knowledge associated with the word stimulus in this or that national culture (Balli, 1955). Within any associative field, nuclear and peripheral reactions can be distinguished. Concerning the volume of a nuclear area and the principles of its allocation scientists adhere to various points of view because of a quite indistinct definition "the most frequent reactions" does not give the chance to select the main characteristics of nuclear associations (Sergiyeva, 2009). However, in our opinion, the choice of allocation criteria significantly depends on the research objectives. As we adhere to the qualitative analysis of the associative fields, we consider not only the nuclear reactions but all associates irrespective of their rate ignoring of which could significantly affect the complete though average image existing in the language consciousness.

\section{Participants}

The material for the research was gathered through the associative experiments that were organized simultaneously among Arabic, Chinese and Russian students. Here it should be mentioned that we tried to interview the equal number of male and female respondents in order to exclude gender influence. The nationalities for the analysis were chosen according to the educational environment of the region where the experiments were organized. At the moment Russia, China, and Iraq have strong and close collaboration in many spheres. Thus, it is becoming urgent to analyze the differences and similarities of their linguistic consciousness in order to build strong relations in the field of education, business, technology, etc.

In any linguistic experiment a researcher, creating the simulated conditions for a participant expects to receive the language material that would be enough for studying and examining this or that problem that he wants to search. In this regard at the first stage of the experiment preparation, the main question arises: what number of respondents should be polled in order to receive representative data. In the practice of psycholinguistics the associative field consisting of 100 responses is considered to be quite sufficient and could be included into the associative dictionary (G. Kiss, 1972; Martinovich, 1993; Goroshko, 2005).

\section{Limitations}

Psycholinguistic experiments use reaction-time methodology to examine language comprehension and production as online processes (MacWhinney, 2001). The unconscious reaction when the choice is made not by a thought, but by language itself offering a prepared fragment from well-known texts is possible only when the time interval between stimulus and reaction is minimized. So that an interviewee has no possibility to think of what to say and how as the concept of association excludes the idea of answer-selection (Zubkova, 1996). Frumkina notes that if there is a selection, there is no associative process (Frumkina, 2001). Thus, in our experiment we gave the respondents the questionnaire of 100 words that were written in their native languages and set the time limit of 15 minutes, We count out that this time limit is enough for this set of questions.

\section{Results and discussion}

As a result of our experiment, we got three associative fields consisting of 100 reactions that served as a base for our research. The number in round brackets shows the number of respondents who gave the same association. Thus, among all the received answers we can distinguish frequent (nuclear) reactions that comprise nearly $46 \%$ of all responses, and less common ones which can help to fulfill and color the general perception of the analyzed image (Sergieva, 2008). 


\section{The analysis of the image "money" in the linguistic consciousness of Arabic students}

Money bank (14), job (13), important (9), work (6), need (6), life (5), everything (5), good (3), means (3), have (2), not everything (2), power (2), happiness (2), coins, house, food, future, way, travel, more more, tree, papers, to live, pleasure, a lot of, dollars, competition, magnificent, collect, to achieve, dream, very important, horizon, rich, great, happy, many, necessary, jobs, dollar, way of living (1).

The associative field of the image "money" consists of 100 answers, with 41 different responses, where the diversity coefficient $(\mathrm{Kp})$ equals 0,41 (Kp was calculated according to the formula: $\mathrm{Kp}=\mathrm{B}: \mathrm{A}$, where $\mathrm{A}$ is the number of reactions, $\mathrm{B}$ is the number of different reactions).

The characteristic of response-reactions from a purely linguistic point of view implies the analysis of their formal-grammatical features. In the given associative field the distribution of answers can be presented in the following way: predicative reactions constituting the predicate group in a two-part sentence with the stimulus word have, to achieve, collect (1); verbal reactions that don't make predicate group travel, to live (1), reactions in the form of word-combinations not everything, more more, very important, way of living (1); word-forms that are adjectives characterizing the word stimulus important (9), good (3), magnificent, reach, great, many, happy, necessary and nominative reactions bank (14), job (13), work (6), need (6), life (5), everything (5), means (3), power (2), happiness (2), coins, house, food, future, way, tree, papers, pleasure, dollars, etc..

Another classification includes distribution of all reactions according to contiguity and similarity (Gak, 1972). Contiguity reactions are the associative pairs that do not have common essential signs in content. A variety of these associations comprises the so-called thematic associations or associations of metonymic type: reactions of source bank (14), job (13), work (6), reactions of importance everything (5), not everything (2), reactions of result house, food (1).

The similarity of verbal associations (similarity of lexical meanings) implies the presence of common semes. Generally, this type includes verbal associations of a metaphorical or epithet type. Thus, these answers are subdivided into determination and classification groups: classification-reactions means (3), coins, papers, dollars, dollar (1); determination ones: coordinated verbs have (2), to achieve, collect (1), uncoordinated verbs to live, travel (1), uncoordinated adjectives of importance important (9), very important, necessary (1) and enthusiasm good (3), great, magnificent (1), coordinated adjectives a lot of, many, more more (1).

In addition to the mentioned types of reactions, we can also distinguish the mediated answers in which the response has no direct relationship with the word-stimulus. The relationship with the stimulus can be viewed only through a third, usually not formally expressed member. Schematically, the relationship, in this case, can be represented as S [human being] - R: nouns need (6), life (5), power (2), happiness (2), future, way, pleasure, dream, horizon, competition adjectives rich, happy and a word combination way of living (1).

Considering verbal associative structures as primitive texts that are viewed as nominations of certain situations, we can highlight the typology of numerous associations based on differences in their construction nomination strategies (Ovchinnikova, 1994). The analyzed associative field can be characterized by the following distribution of thematic, syntagmatic and paradigmatic pairs that constitute $72 \%, 19 \%$ and $9 \%$ of the total number of answers respectively.

The nuclear reactions include contiguity reactions of place bank (14), source job (13), work (6), necessity need (6) and determination of value important (9). All of the frequent reactions recorded in the associative field present the relevance of the studied

XLinguae, Volume 12 Issue 2, April 2019, ISSN 1337-8384, eISSN 2453-711X 
image as a value that is considered to be a reward for hard work. The selected semantic groups prove the significance of the nuclear answers.

1. Semantic group of source and place: bank (14), job (13), work (6), jobs (1).

2. Semantic group of necessity: important (9), need (6), life (5), everything (5), very important, necessary (1).

In this group, we can also distinguish such reaction as not everything (2) that indicates that money is not so important in comparison with other life values.

3. Semantic group of emotionally colorful positive answers: attributive good (3), magnificent, rich, great, happy (1); nominative happiness (2), pleasure, dream, horizon (1).

4. Semantic group of possibilities that money gives: power (2), future, way, way of living, competition (1).

5. Semantic group of classification-reactions: means (3), coins, papers, dollars, dollar (1).

6. Semantic group of action reactions: have (2), collect, to achieve, travel, to live (1).

7. Semantic group of reactions characterizing the sum: more more, a lot of, many (1).

8. Semantic group of results: house, food (1).

9. The reaction that forms the name of the plant with the studied word money tree: tree (1).

The first semantic field constitutes the nuclear base for the analyzed image as it represents the general source for getting money. Here it should be mentioned that we deliberately combined two notions (source and place) because the reaction bank can serve both as a source when for example we take the credit in a bank and a place where we can store money. The second important semantic group shows the life necessity and dependence on the image as the respondents view it as a crucial and necessary element of life. This model of image perception is highlighted by the possibility reactions displaying that for the Arabic students, money is a way of living, it is the opportunity to buy food, house, to build their future and to possess the power in order to achieve happiness (2), dream. Thus, we can state that the connotation of the studied image is rather positive that can be proved by the semantic group of emotionally colorful answers. The less numerous semantic fields include the amount of money that students want to have; the action reactions that show various types of activities that they can do with money and the classification reactions that demonstrate that for the respondents, money is associated not with the native monetary currency but with dollars and simply means of living.

\section{The analysis of the image "money" in the linguistic consciousness of Chinese students}

Money Yuan (9), dollar (7), monkey (7), rich (7), useful (6), much (5), happy (4), little (3), like (3), more (3), work (3), save (2), good (2), many (2), house (2), buy (2), more is the better, money is tool, power, pain, storage, bribe, good life, make, incalculable, a lot, fun, do some shopping, pay, weapon, building, economy, job, happiness, stock, paper, smile, dollars, good thing, time, money, everything, shopping, I want more and more, monkey?, cake, evil, red paper, great.

The associative field of the image, money consists of 102 answers, with 49 different responses, where the diversity coefficient $(\mathrm{Kp})$ equals 0,48 and can be characterized by the following distribution of thematic, syntagmatic and paradigmatic pairs $47 \%$, $33 \%$, and $20 \%$.

According to the formal-grammatical classification, all the answers given in the associative field can be grouped into predicative reactions constituting the predicate 
group in a two-part sentence with the stimulus word like (3), buy (2), save (2), make, pay (1); reactions in the form of word-combinations good thing, good life, do some shopping, red paper (1); sentence reactions more is the better, money is tool, I want more and more (1); adjectives rich (7), useful (6), happy (4), little (3), much (5), more (3), good (2), many (2), incalculable, great (1) and nominative reactions dollar (7), monkey (7), work (3), house (2), power, pain, bribe, weapon, building, happiness, evil, time, money, etc. .

Reactions of similarity possessing the process sign are depicted by coordinated verbs like (3), buy (2), pay, save, make (1). Classification reactions of a metaphoric type are presented by the most frequent reactions Yuan (9), dollar (7) and less numerous paper, red paper, dollars, money (1). Reactions of an epithet type are subdivided into attributive answers possessing the direct description of the analyzed image (determination) much (5), little (3), more (3), incalculable, a lot (1) and mediated attributive answers S [human being] - R: rich (7), happy (4). Another group of nominative answers that are related to the studied image by means of the third element $\mathrm{S}$ [human being] - R can be illustrated by the following list: smile, happiness, good life, fun, power, everything; $\mathrm{S}$ [working process] - R: time; $\mathrm{S}$ [evil] - R: evil, pain (1). Contiguity reactions in the analyzed associative field are reactions of source work (3), job; evaluation useful (6), good (2), great; answers connected with the ways of money spending house (2), do some shopping, cake, shopping, bribe, building, weapon (1), economic-related reactions storage, economy, stock (1) and word combination money is tool. The answer monkey (7) is considered to be functionalsituation contiguity reactions where the associative pair is viewed as a stable word combination. More is the better, I want more and more (1) are examples containing the personal evaluation of the image "money".

The most frequent reactions Yuan (9), dollar (7), monkey (7), rich (7), useful (6), much (5), happy (4) reveal the general perception of the analyzed image and constitute $46 \%$ of the total number of responses. They indicate that the most typical associative strategies are classification Yuan, dollar, functionalization monkey, attributions rich, useful, much.

Semantically all the responses can be grouped into:

1. Semantic group of emotionally colorful positive answers: attributive rich (7), useful (6), happy (4), good (2), great (1). nominative smile, happiness, good life, fun, everything, power (1).

2. Semantic group of classification-reactions: Yuan (9), dollar (7), paper, red paper, dollars, money, money is tool (1).

3. Semantic group of reactions characterizing the sum: much (5), little (3), more (3), many (2), incalculable, a lot, more is the better, I want more and more (1).

4. Semantic group of action reactions: like (3), save (2), buy (2), pay, make (1).

5. Semantic group of cultural reaction: monkey (7), monkey? (1).

6. Semantic group of results: house (2), do some shopping, cake, shopping, building (1).

7. Semantic group of source: work (3), job (1).

8. Semantic group of answers with a negative connotation: bribe, weapon, pain, evil (1).

9. Semantic group of economic-related reactions: storage, economy, stock (1).

10. Semantic group of time: time (1).

11. Semantic group of possibilities that money gives: power (1).

12. Semantic group of place: storage (1).

The studied image in linguistic consciousness of the Chinese students has strong associations with the national currency (Yuan) and foreign currency (dollar); thus it underlines the strength of the national monetary system in comparison to the USA

XLinguae, Volume 12 Issue 2, April 2019, ISSN 1337-8384, eISSN 2453-711X 
one. Money for Chinese students is not the living necessity as there are practically no replies showing its importance on the level of ordinary domestic activities. It serves for them as a source of happiness, good life, fun, shopping, that is why there are many responses that refer to their wish to possess a big sum much, more, incalculable, a lot, more is the better, I want more and more. However, only 3 out of 102 respondents relate money to work and job, so as a result, the associative field lacks the answers related to the difficulty of its earning. That is why the general connotation of the analyzed image is positive rich (7), useful happy, good, great. Although, there are some answers that demonstrate situations when money can cause evil: bribe, weapon, pain. The given analysis allows us to agree that Asian cultures give more salience to subjective well-being social harmony aspects and do not emphasize personal success in its construction (Telef and Furlong, 2017).

\section{The analysis of the image "money" in the linguistic consciousness of Russian students}

Money work (10), power (10), wealth (6), evil (4), no (3), opportunity (3), opportunities (2), success (2), means (2), necessity (2), time (2), dollar (2), not enough (2), dosh, resorts, little, purse, education, have, dirty, way of living, beautiful life, business, big, Wall Street, green papers, help, luxury, desire, wish, purchases, pocket, banknotes, rubles, there are some, papers, dollars, good, earn, waste, moola, happiness, destruction, not everything, excellent, car, purpose, rings, joy, prestige, salary, well, garbage (1).

The associative field of the image, money consists of 100 answers, with 53 different responses, where the diversity coefficient $(\mathrm{Kp})$ equals 0,53 and can be characterized by the following distribution of thematic, syntagmatic and paradigmatic pairs $82 \%$, $5 \%$, and $13 \%$.

The characteristic of responses from a purely linguistic point of view implies the analysis of their formal-grammatical features. In the given associative field we can distinguish: predicative reactions constituting the predicate group in a two-part sentence with the stimulus word have, earn, ring (1); reactions in the form of wordcombinations not enough (2), way of living, beautiful life, not everything, green notes; sentence reactions there are some; interjection no (3); adverb well (1); proper name Wall Street (1); adjectives little, dirty, pocket, big, good, excellent (1); and the most numerous group of answers - nominative reactions work (10), power (10), wealth (5), evil (4), opportunity (3), opportunities (2), success (2), means (2), necessity (2), time (2), etc..

Contiguity reactions in the analyzed associative field are grouped in the following way: reactions of source work (10), business, education (1); reactions of importance necessity (2), not everything (1); reactions of result wealth (6), luxury, purchases, waste, car (1); place purse, Wall Street (1); sum not enough (2), there are some (1); evaluation good, excellent, well (1). Similarity can be presented by classificationreactions means (2), dollar (2), dosh, green notes, banknotes, rubles, papers, dollars, moola, salary (1) and determination ones: uncoordinated adjective black (1), coordinated adjectives little, dirty, pocket, big (1), coordinated verbs rings, earn, have (1). Mediated answers S [work] - R: time (2); S [human being] - R: nouns power (10), no (3), opportunity (3), opportunities (2), success (2), help, desire, wish, happiness, purpose, prestige (1) and a word combination way of living (1); S [evil] $\mathrm{R}$ : evil (4), destruction, garbage (1).

The most popular reactions include responses of source work (10), possibility power (10), result wealth (6) and emotionally negative reaction evil (4). All of the frequent reactions recorded in the associative field present the general perception of the image, money that is verified by the selected semantic groups: 
1. Semantic group of possibilities that money gives: power (10), opportunity (3), opportunities (2), way of living, help (1).

2. Semantic group of results: wealth (6), success (2), beautiful life, resorts, prestige, luxury, purchases, car (1).

3. Semantic group of classification-reactions: means (2), dollar (2), dosh, green notes, banknotes, rubles, papers, dollars, moola, salary (1).

4. Semantic group of source: work (10), business, education (1).

5. Semantic group of emotionally colorful positive answers: attributive little, pocket, big, good, excellent, well (1); nominative desire, joy, wish, happiness (1).

6. Semantic group of answers with a negative connotation: nominative: evil (4), destruction, waste, garbage (1); attributive: dirty, black (1).

7. Semantic group of reactions characterizing the sum: not enough (2), little, there are some (1).

8. Semantic group of necessity: necessity (2), purpose (1).

In this group such a reaction as not everything can be distinguished, that indicates that money is not so important in comparison with other life values.

9. Semantic group of action reactions: rings, earn, have (1).

10. Semantic group of personal answers: no (3).

11. Semantic group of place: purse, Wall Street (1).

12. Semantic group of time: time (2).

The most crucial aspect of money for Russian students is the possibilities and opportunities that are accessible to a person who has money. Among the most important they distinguish power that occupies the first position and after it the opportunities to gain wealth, success, prestige. Thus, the emotional spectrum of the analyzed image is evaluated as good, excellent, well and characterized by such positive nominative reactions as desire, joy, wish, happiness. At the same time, the semantic group of the source has only $12 \%$ of the total number of answers that reveals that students treat money as something that they constantly lack not enough (2), little without paying attention to the process of its earning. However, it should be mentioned that although they speak about money shortage, they do not highlight its necessity, that means that they have enough money for living, but due to their ambitions they dream of luxury and wealth.

\section{Conclusion}

The given analyses show the differences and similarities in the perception of the studied image. The general types of response-reactions to the studied image in linguistic consciousness of Arabic, Chinese and Russian students from the linguistic point can be presented in Table 1 .

Table 1: General types of response-reaction

\begin{tabular}{|c|c|c|c|c|}
\hline \multicolumn{2}{|c|}{ Types of reaction } & $\begin{array}{c}\text { Money } \\
\text { (Arabic } \\
\text { students) }\end{array}$ & $\begin{array}{l}\text { Money } \\
\text { (Chinese } \\
\text { students) }\end{array}$ & $\begin{array}{l}\text { Money } \\
\text { (Russian } \\
\text { students) }\end{array}$ \\
\hline \multicolumn{2}{|l|}{ Sentence reactions } & - & $2,9 \%$ & $1 \%$ \\
\hline \multirow{2}{*}{ Word-combinations } & coordinated & $1 \%$ & - & $2 \%$ \\
\hline & uncoordinated & $3 \%$ & $3,8 \%$ & $4 \%$ \\
\hline \multicolumn{2}{|c|}{$\begin{array}{l}\text { Predicative reactions constituting the } \\
\text { predicate group }\end{array}$} & $3 \%$ & $8,7 \%$ & $3 \%$ \\
\hline
\end{tabular}

XLinguae, Volume 12 Issue 2, April 2019, ISSN 1337-8384, eISSN 2453-711X 


\begin{tabular}{|c|c|c|c|c|}
\hline \multicolumn{2}{|c|}{ Infinitive forms } & $2 \%$ & - & - \\
\hline \multicolumn{2}{|l|}{$\mathrm{V}$-ing forms } & - & - & - \\
\hline \multicolumn{2}{|c|}{$\begin{array}{l}\text { Verbal reactions that do not make } \\
\text { predicate group }\end{array}$} & $2 \%$ & - & - \\
\hline \multirow[t]{3}{*}{ Adjectives } & coordinated & $1 \%$ & $12,6 \%$ & $3 \%$ \\
\hline & uncoordinated & $17 \%$ & $19,4 \%$ & $3 \%$ \\
\hline & verbal & - & - & - \\
\hline \multicolumn{2}{|l|}{ Adverbs } & - & - & $1 \%$ \\
\hline \multicolumn{2}{|l|}{ Nouns } & $73 \%$ & $52,6 \%$ & $79 \%$ \\
\hline \multicolumn{2}{|l|}{ Interjections } & - & - & $3 \%$ \\
\hline \multicolumn{2}{|l|}{ Proper name } & - & - & $1 \%$ \\
\hline
\end{tabular}

The majority of responses written by the interviewees are non-communicative wordforms that refer to the inanimate models of speech synthesized in the experimental conditions. The percentage distribution of the responses is not homogeneous. However, the most typical types of word-form such as nomination and determination can be explained by the formal grammatical characteristics of the word stimulus.

The placement of responses according to the level of relations among the elements of associative pairs can be illustrated in Table 2 .

Table 2: Placement of responses according to the level of relations

\begin{tabular}{|c|c|c|c|c|}
\hline \multicolumn{2}{|c|}{ Level of relations } & $\begin{array}{l}\text { Money } \\
\text { (Arabic } \\
\text { students) }\end{array}$ & $\begin{array}{l}\text { Money } \\
\text { (Chinese } \\
\text { students) }\end{array}$ & $\begin{array}{c}\text { Money } \\
\text { (Russian } \\
\text { students) }\end{array}$ \\
\hline \multicolumn{2}{|c|}{ Contiguity reactions } & $42 \%$ & $36 \%$ & $47 \%$ \\
\hline \multirow{2}{*}{$\begin{array}{l}\text { Similarity } \\
\text { reactions }\end{array}$} & determination & $26 \%$ & $22 \%$ & $6 \%$ \\
\hline & classification & $7 \%$ & $21 \%$ & $13 \%$ \\
\hline \multicolumn{2}{|c|}{ Mediated answers } & $25 \%$ & $21 \%$ & $34 \%$ \\
\hline
\end{tabular}

As we can see from the table, the following distribution of reactions is also largely determined by the lexico-grammatical properties of the word-stimulus. At the same time, it should be mentioned, that both Russian and Arabic groups of respondents tend to give more reactions based on the principle of continuity, while Chinese gave more reactions of similarity that consist of determination and classification answers. Here it is important to state that Chinese students gave more classification responses, while Arabic students showed equal distribution of similarity reactions. As for the Russian interviewees, they described the image "money" mostly through mediated answers and associative pairs that do not have common essential signs in content, thus associated it with some other objects of reality. Consequently, the obtained data confirms that the relations of contiguity and similarity, reflecting the main types of relations between the phenomena of the objective world, constitute the base for the creation and consolidation of verbal associations for Arabic and Chinese people, while the continuity and mediated answers are more typical for the Russian respondents.

From a psycholinguistic point of view, it is also important to evaluate the differences in perception of the studied images. In Table 3 semantic group ranking is presented.

Table 3: Semantic group ranking

\begin{tabular}{|c|c|c|c|}
\hline Rank & $\begin{array}{c}\text { Money } \\
\text { (Arabic students) }\end{array}$ & $\begin{array}{c}\text { Money } \\
\text { (Chinese students) }\end{array}$ & $\begin{array}{c}\text { Money } \\
\text { (Russian students) }\end{array}$ \\
\hline 1 & $\begin{array}{c}\text { Semantic group of } \\
\text { source and place }\end{array}$ & $\begin{array}{c}\text { Semantic group of } \\
\text { emotionally colorful }\end{array}$ & $\begin{array}{c}\text { Semantic group of } \\
\text { possibilities 17\% }\end{array}$ \\
\hline
\end{tabular}




\begin{tabular}{|c|c|c|c|}
\hline & $34 \%$ & $\begin{array}{c}\text { positive answers } \\
26 \%\end{array}$ & \\
\hline 2 & $\begin{array}{c}\text { Semantic group of } \\
\text { necessity } \\
29 \% \\
\end{array}$ & $\begin{array}{c}\text { Semantic group of } \\
\text { classification-reactions } \\
21 \% \\
\end{array}$ & $\begin{array}{c}\text { Semantic group of } \\
\text { results } \\
13 \% \\
\end{array}$ \\
\hline 3 & $\begin{array}{c}\text { Semantic group of } \\
\text { emotionally colorful } \\
\text { positive answers } \\
12 \%\end{array}$ & $\begin{array}{c}\text { Semantic group of } \\
\text { reactions } \\
\text { characterizing the sum } \\
17 \%\end{array}$ & $\begin{array}{l}\text { Semantic group of } \\
\text { classification- } \\
\text { reactions } \\
12 \%\end{array}$ \\
\hline 4 & $\begin{array}{c}\text { Semantic group of } \\
\text { possibilities } \\
8 \%\end{array}$ & $\begin{array}{c}\text { Semantic group of } \\
\text { action reactions } \\
9 \%\end{array}$ & $\begin{array}{c}\text { Semantic group of } \\
\text { source } \\
12 \%\end{array}$ \\
\hline 5 & $\begin{array}{c}\text { Semantic group of } \\
\text { classification-reactions } \\
7 \%\end{array}$ & $\begin{array}{c}\text { Semantic group of } \\
\text { cultural reaction } \\
8 \%\end{array}$ & $\begin{array}{c}\text { Semantic group of } \\
\text { emotionally colorful } \\
\text { positive answers } \\
10 \% \\
\end{array}$ \\
\hline 6 & $\begin{array}{c}\text { Semantic group of } \\
\text { action reactions } \\
6 \%\end{array}$ & $\begin{array}{l}\text { Semantic group of } \\
\text { results } \\
6 \%\end{array}$ & $\begin{array}{c}\text { Semantic group of } \\
\text { answers with a } \\
\text { negative connotation } \\
9 \%\end{array}$ \\
\hline 7 & $\begin{array}{l}\text { Semantic group of } \\
\text { reactions characterizing } \\
\text { the sum } \\
3 \%\end{array}$ & $\begin{array}{c}\text { Semantic group of } \\
\text { source } \\
4 \%\end{array}$ & $\begin{array}{l}\text { Semantic group of } \\
\text { reactions } \\
\text { characterizing the } \\
\text { sum } \\
4 \%\end{array}$ \\
\hline 8 & $\begin{array}{l}\text { Semantic group of } \\
\text { results } \\
2 \%\end{array}$ & $\begin{array}{c}\text { Semantic group of } \\
\text { answers with a } \\
\text { negative connotation } \\
4 \%\end{array}$ & $\begin{array}{c}\text { Semantic group of } \\
\text { necessity } \\
4 \%\end{array}$ \\
\hline 9 & $\begin{array}{c}\text { The reaction that forms } \\
\text { the name of the plant } \\
\text { with the studied word } \\
1 \%\end{array}$ & $\begin{array}{l}\text { Semantic group of } \\
\text { economic-related } \\
\text { reactions } \\
3 \%\end{array}$ & $\begin{array}{c}\text { Semantic group of } \\
\text { action reactions } \\
3 \%\end{array}$ \\
\hline 10 & - & $\begin{array}{c}\text { Semantic group of } \\
\text { time } \\
1 \% \\
\end{array}$ & $\begin{array}{c}\text { Semantic group of } \\
\text { personal answers } \\
3 \% \\
\end{array}$ \\
\hline 11 & - & $\begin{array}{c}\text { Semantic group of } \\
\text { possibilities } \\
1 \%\end{array}$ & $\begin{array}{c}\text { Semantic group of } \\
\text { place } \\
2 \%\end{array}$ \\
\hline 12 & - & $\begin{array}{c}\text { Semantic group of } \\
\text { place } \\
1 \% \\
\end{array}$ & $\begin{array}{c}\text { Semantic group of } \\
\text { time } \\
2 \% \\
\end{array}$ \\
\hline
\end{tabular}

Summing up, the image "money" is characterized by a great number of emotionally colorful reactions that were given by respondents of each group. However, Chinese students highlight the emotional aspect of money more than other respondents. It is proved by the rank of the semantic field of emotionally colorful positive answers among other groups. The Arabic students are more concentrated on its importance and the source of earning, while Russian interviewees tend to evaluate the image "money" according to the possibilities and opportunities that it provides. 
The Chinese students refer the studied image to the economic notions Yuan, dollar, storage, economy, stock, concentrate much attention on the sum that they want to have while speaking less about the source of earning. The same perception is similar to the Russian students, who distinguish dollars and rubles as the main monetary items, although they are less concentrated on the sum that they want to have and just underline that at the time of the experiment they had not enough money to reach the goals: wealth, beautiful life, resorts, luxury, car, etc. As for the Arabic students, they pay less attention to the sum of money that they have, because getting at least some is real happiness for them, as they will get the opportunity to build their future. Therefore, there are no negative reactions among their answers contrary to the Russian and Chinese students, who treat this image not only in a positive way but also associate money with the problems of modern society: bribe, weapon, pain, evil, destruction.

The offered model of psycholinguistic image analysis is universal and can be used for studying and describing any other images.

\section{Acknowledgment}

The work was supported by Act 211 Government of the Russian Federation, contract № 02.A03.21.0011

\section{Bibliographic references}

ALEFIRENKO, N. 2015. Language as a State of Ethno-Cultural Consciousness. In: Linguae, vol. 8, pp. 2-18. doi: 10.18355/XL.2015.08.03.2-18

BALLY, S. 1955. French stylistics. Moscow: Nauka. 416 p. ISBN 5-8360-0407-2

BURCHELL, B. J., - COUTTS, A. P. 2018. The Experience of Self-Employment Among Young People: An Exploratory Analysis of 28 Low- to Middle-Income Countries. In: American Behavioral Scientist, 000276421879424. doi:10.1177/0002764218794240

BURCU BAYRAM, A. 2016. Values and Prosocial Behaviour in the Global Context: Why Values Predict Public Support for Foreign Development Assistance to Developing Countries. In: Journal of Human Values, vol 22, issue 2, pp. 93-106. doi.org/10.1177/0971685815627749

CHILDS, B. 2018. Student Voice and Linguistic Identity: Digital Badging as a Tool for Retention of First Year and First Generation Undergraduates. In: Journal of English Linguistics, vol. 46 issue 3, pp. 186-198. doi.org/10.1177/0075424218783444 DEESE, J. 1962. Form class and determinants of association. In: Journal of learning and verbal behavior. Washington, pp. 79-84. ISSN 0022-5371

DEINEKA, O.S. 2004. Symbolization of money: the experience of empirical research text. In: Problems of Economic Psychology, vol.1, pp. 207-241. ISSN: 2223-5760

FIELD, J. 2004. Psycholinguistics: The Key Concepts. "Psychology Press". 366 p. ISBN: 041525891X

FRUMKINA, R.M. 2001. Psycholinguistics. Moscow: "Academy”. 320 p. ISBN 57695-0726-8

GAK, V.G. 1971. To the problem of semantic syntagmatics. In: Problems of structural linguistics, pp. 367-395.

GARNHAM, A. Psycholinguistics: Central Topics. "Psychology Press". 284 p. ISBN: 9780415045520

GOGGIN, G. 2013. Youth culture and mobiles. In: Mobile Media \& Communication, 1(1), pp. 83-88. doi:10.1177/2050157912464489

GOROSHKO, E.I. 2005. Problems of the free associative experiment. In: Proceedings of Volgograd state pedagogical University, vol.3, pp. 53-61.ISSN 1815-9044

GRONBECK-TEDESCO, J.A. 2017. Culture and Crisis in the Age of Tolerance. In: Journal of Language, Literature and Culture, vol. 64, issue 3, pp. 213-227. doi: $10.1080 / 20512856.2017 .1402478$ 
HAMPTON, M. 2013. Money as social power: The economics of scarcity and working class reproduction. In: Capital \& Class, 37 (3), pp. 373-395. doi: $10.1177 / 0309816813502762$

INNIS, R.E. 2016. Between philosophy and cultural psychology: Pragmatist and semiotic reflections on the thresholds of sense. In: Culture \& Psychology, vol. 22, issue 3, pp. 331-361. doi: 10.1177/1354067X16638847

JUNG, J. 1966. Experimental studies of factors affecting word associations. In: Psychological Bulletin, vol. 66, n. 2, pp. 125-133. doi.org/10.1037/h0023570

KISS, G. - ARMSTHONG, C. - MILROY, R. 1972. The Associative Thesaurus of English. Edinburgh: Univ. of Edinb., Speech and Communication Unit.

KELLY, M. L. 1996. Handbook of Psycholinguistics. Language and Speech, vol. 39 (1), pp. 99-107. doi: 10.1177/002383099603900107

LEONTIEV, A.A. 1993. Linguistic consciousness and the worldview. In: Language and Consciousness: Paradoxical Rationality, pp. 16-21.

MACWHINNEY, B.J. 2001. Psycholinguistics: Overview. In: International Encyclopedia of the Social and Behavioral Sciences, pp. 12343-12349. ISBN 9780080430768

MARTINOVICH, G.A. 1993. Experience of complex study of associative experiment data. In: Questions of psychology, vol.2, pp. 93-99. ISSN 0042-8841

MIKLASHEVSKY. A. 2018. Perceptual Experience Norms for 506 Russian Nouns: Modality Rating, Spatial Localization, Manipulability, Imageability and Other Variables, In: Journal of Psycholinguistic research, vol. 47, issue 3, pp. 641-661. doi: 10.1007/s10936-017-9548-1

MING CHUNG, YU. 2005. Sociolinguistic Competence in the Complimenting Act of Native Chinese and American English Speakers: A Mirror of Cultural Value. In: Language and speech, vol. 48, issue 1, pp. 91-119. doi: $10.1177 / 00239309050480010501$

MINKOV, M. - HOFSTEDE, G. 2011. Is National Culture a Meaningful Concept? In: Cross-Cultural Research, vol. 46 (2), pp. 133-159. doi: $10.1177 / 1069397111427262$

NGUYEN, V.T. 2016. The cross-cultural analysis of the metaphorical conceptualization of happiness in English and Vietnamese. In: Review of Cognitive Linguistics, vol.14, n. 2, pp. 275-302. doi: 10.1075//rcl.14.2.02ngu

OVCHINNIKOVA, I.G. 1994. Association and utterance: structure and semantics. Russia: Perm. 124 p. ISBN 5-230-09396-X

ROBINSON, M.D. - BOYD R.L. - FETTERMAN A.K. - PERSICH M.R. 2017. The Mind Versus the Body in Political (and Nonpolitical) Discourse: Linguistic Evidence for an Ideological Signature in U.S. Politics. In: Journal of Language and Social Psychology, vol. 36, issue 4, pp. 438-461. doi.org/10.1177/0261927X16668376

SERGIEVA, N.S. 2008. The nuclear base of linguistic consciousness: content and structure. In: Bulletin of Vyatka State University, vol. 2, issue3, pp. 19-21. ISSN 2541-7606

SERGIEVA, N.S. 2009. The space and time of life in the Russian language consciousness. SPb,: Publishing House "Nauka”. ISBN 978-5-02025-253-0

SOLER-I-MARTI, R. - FERRER-FONS, M. 2015. Youth Participation in Context: the Impact of Youth Transition Regimes on Political Action Strategies in Europe. In: The Sociological Review, 63(2_suppl), pp. 92-117. doi:10.1111/1467-954x.12264

SOROKIN, Yu.A. 2007. Ethnic conflictology (theoretical and experimental fragments). Moscow: Institute for Risk Problems. 120 p. ISBN 5-317-01585-5

STELLAR, J. E. - Willer, R. 2013. The Corruption of Value. In: Social Psychological and Personality Science, 5(1), pp. 60-66. doi:10.1177/1948550613484770

XLinguae, Volume 12 Issue 2, April 2019, ISSN 1337-8384, eISSN 2453-711X 
TARASOV, E.F. 1996. Intercultural communication - a new ontology of linguistic consciousness analysis. In: Ethnocultural specificity of linguistic consciousness, pp. 7-22.

TAYLOR, D.M. - USBORNE, E. 2007. Is the Social Psychology of Language a Genuine Field of Study. In: Journal of Language and Social Psychology, vol. 26, issue 2, pp. 204-211. doi.org/10.1177/0261927X07300081

TELEF, B.B. - FURLONG, M.J. 2017. Social and Emotional Psychological Factors Associated With Subjective Well-Being: A Comparison of Turkish and California Adolescents. In: Cross-Cultural Research, vol. 51, n. 5, pp. 1-30. doi.org/10.1177/1069397117694815

UFIMTSEVA N.V. 2003. Linguistic consciousness as a reflection of ethno sociocultural reality. In: Questions of Psycholonguistics, vol.1, pp. 102-110. ISSN 2077-5911

UFIMTSEVA, N.V. - CHERKASOVA, G.A. - KARAULOV, YU.N. - TARASOV, E.F. 2004. Slavic Associative Dictionary. Moscow. 791 p.

UFIMTSEVA, N.V. 2006. Ethnopsycholinguistics: yesterday and today. In: Questions of psycholinguistics, vol.4, pp. 92-100. ISSN 2077-5911

USHAKOVA, T.N. 2000. Linguistic consciousness and the principles of his research. In: Linguistic consciousness and the image of the world, pp. 13-23.

VASILYEVA, S.P. 2016. Money as a value in the linguistic co-knowledge of Russian Prieniseyskoy Siberia. In: Vestnik KSPU. Vol. 3, issue 37, pp. 158-165. ISSN 19950861

WIERZBICKA, A. 1992. Semantics, Culture and cognition: Universal human concepts in culture-specific configurations. Oxford \& New York: Oxford University Press. 487p. ISBN 160129865X

WIERZBICKA, A. 2005. In Defense of "Culture." In: Theory \& Psychology, vol. 15(4), pp. 575-597. doi:10.1177/0959354305054752

ZALEVSKAYA, A.A. 2005. Psycholinguistic research. Word. Text: Selected Works. Moscow "Gnozis". 543 p. ISBN 5-7333-0145-7

ZHALSANOVA, ZH.B. 2017. The image of "Darhan / Blacksmith" in the Buryat culture (psycholinguistic significance). In: Vestnik Tomskogo Gosudarstvennogo Universiteta, Filologiya, issue 45, pp. 89-99. doi: 10.17223/19986645/45/6

ZITTOUN, T. - GILLESPIE A. 2012 Internalization: How culture becomes mind. In: Culture \& Psychology, vol. 21, issue 4, pp. 477-491. doi.org/10.1177/1354067X15615809

ZUBKOVA, T.I. - SAHARNIY L.V. - SHTERN A.S. 1996. Psycholinguistics. St. Petersburg state University. 267 p.

Words: 7005

Characters: 46812 (26,56 standard pages)

assoc. prof. Candidate in Philology Ekaterina Balandina

Department of Foreign Languages

Federal State Autonomous Educational Institution of Higher Education

"South Ural State University (national research university)"

76 Lenin pr.454080 Russian Federation

balandinaes@susu.ru

assoc. prof. Candidate in Philology Tatiana Peredrienko

Department of Foreign Languages

Federal State Autonomous Educational Institution of Higher Education

"South Ural State University (national research university)"

76 Lenin pr.454080 Russian Federation

peredrienkoti@susu.ru 